05

\title{
Влияние легирования алюминием и железом на структуру, магнитные и магнитокалорические свойства многокомпонентных сплавов $\mathrm{Tb}-\mathrm{Dy}-\mathrm{Ho}-\mathrm{Co}$
}

\author{
(C) Г.А. Политова, ${ }^{1}$ Г.С. Бурханов, ${ }^{1}$ И.С. Терешина, ${ }^{1,2}$ Т.П. Каминская, ${ }^{2}$ В.Б. Чжан, ${ }^{1}$ Е.А. Терешина ${ }^{3}$ \\ ${ }^{1}$ Институт металлургии и материаловедения им. А.А. Байкова РАН, \\ 119991 Москва, Россия \\ ${ }^{2}$ Московский государственный университет им. М.В. Ломоносова, \\ 119991 Москва, Россия \\ ${ }^{3}$ Институт фоизики Чешской АН, \\ 18221 Прага, Чехия \\ e-mail: gpolitova@gmail.com
}

(Поступило в Редакцию 18 июля 2016 г.)

Выполнено комплексное исследование структуры, фазового состава, особенностей топологии поверхности, магнитных и магнитотепловых свойств многокомпонентных соединений $\mathrm{Tb}_{0.3} \mathrm{Dy}_{0.35} \mathrm{Ho}_{0.35} \mathrm{Co}_{1.75} \mathrm{~T}_{0.25}$ $(T=\mathrm{Al}, \mathrm{Fe})$. Установлены особенности изменения структуры и функциональных свойств при частичном замещении в 3d-подрешетке соединений $\mathrm{RCo}_{2}$ атомов кобальта атомами алюминия или железа.

DOI: 10.21883/JTF.2017.04.44316.1995

\section{Введение}

Фазовые переходы в Лавес-фазах типа $\mathrm{RCo}_{2}$ могут сопровождаться гигантскими магнитострикционными деформациями, а также заметным магнитокалорическим эффектом (МКЭ), вызванным изменением магнитной составляющей энтропии [1-4]. Используя различные комбинации редкоземельных металлов (Р3М), а также частичное замещение атомов кобальта в 3d-подрешетке атомами других металлов, можно управлять их свойствами и использовать в качестве основы для создания новых функциональных материалов [5-14].

В настоящей работе главным образом проанализированы закономерности изменения температуры Кюри, магнитокалорического эффекта, морфологии поверхностных слоев образцов лавес-фазы $\mathrm{RCo}_{2}$ при частичном замещении кобальта. В качестве объектов исследования были выбраны три состава: $\mathrm{Tb}_{0.3} \mathrm{Dy}_{0.35} \mathrm{Ho}_{0.35} \mathrm{Co}_{2}, \mathrm{~Tb}_{0.3} \mathrm{Dy}_{0.35} \mathrm{Ho}_{0.35} \mathrm{Co}_{1.75} \mathrm{Al}_{0.25}$ и $\mathrm{Tb}_{0.3} \mathrm{Dy}_{0.35} \mathrm{Ho}_{0.35} \mathrm{Co}_{1.75} \mathrm{Fe}_{0.25}$, соотношение редкоземельных компонентов в которых оставалось постоянным.

\section{1. Синтез соединений}

$$
\begin{aligned}
& \mathrm{Tb}_{0.3} \mathrm{Dy}_{0.35} \mathrm{Ho}_{0.35} \mathrm{Co}_{1.75} \mathrm{~T}_{0.25}(T=\mathrm{Fe}, \mathrm{Al}) \\
& \text { и рентгеноструктурный анализ }
\end{aligned}
$$

В настоящей работе использовались исходные редкоземельные компоненты с пониженным содержанием металлических и газообразующих примесей. Для этого тербий, диспрозий и гольмий подвергались дополнительной вакуумной дистилляции (сублимации). Синтез соединений прямым сплавлением проводился в дуговой электропечи фирмы Leybold-Heraeus в атмосфере гелия при избыточном давлении в камере, равном $1.1 \mathrm{~atm}$.
Таким образом, исключались побочные примесные эффекты. Для получения однородных по составу образцов проводилась их трехкратная переплавка с последующим гомогенизирующим отжигом в вакуумированных кварцевых ампулах при температуре $900^{\circ} \mathrm{C}$ в течение одного месяца.

Фазовый состав синтезированных соединений контролировался до и после отжига методом рентгеноструктурного анализа. Регистрация рентгенодифракционных спектров выполнена на рентгеновском дифрактометре Ultima IV фирмы Rigaku с вертикальным гониометром и высокоскоростным полупроводниковым детектором $\mathrm{D} / \mathrm{teX}$, в $\mathrm{Cu} K_{\alpha}$-излучении, шаг $0.02^{\circ}$, скорость съемки $2 \% \mathrm{~min}$, интервал $2 \theta-9-100^{\circ}$. Для проведения фазового качественного и количественного анализа был использован программный комплекс PDXL японской фирмы Rigaku, интегрированный с международной базой данных ICDD. B образцах до отжига наряду с основной фазой типа $\mathrm{MgCu}_{2}$ было установлено незначительное количество примесной фазы $\mathrm{RCo}_{3}$, которая была образована в результате неполного прохождения перитектической реакции, что следует из анализа соответствующей фазовой диаграммы. Наличие данной фазы не было обнаружено после проведения отжига.

\section{2. Экспериментальные методы исследования}

\section{Атомно-силовая микроскопия (АСM)}

На современном этапе развития материаловедения АСМ становится все более востребованной, поэтому рассмотрим этот метод более подробно. Разрешающая способность метода по горизонтали 0.1-1 nm, по вертикали $0.01 \mathrm{~nm}$ [15]. Повышенная разрешающая спо- 
собность по отношению к вертикальной координате позволяет получить профиль поверхности твердого тела с размерами особенностей рельефа, соизмеримыми с отдельными атомами.

Наблюдение объемного рельефа поверхности в настоящей работе в микро- и наномасштабах позволяет получить дополнительную информацию о зернистости синтезируемой фазы, степени ее дисперсности, морфологии отдельных зерен, однородности фазового состава, дефектах кристаллической структуры и т.д. Топология поверхности отражает особенности структуры образцов. Эффективность использования АСМ повышается в сочетании с другими методами исследования, такими как просвечивающая и сканирующая электронная микроскопия.

Топология поверхности синтезированных образцов типа фаз Лавеса $\mathrm{RCo}_{2}$ исследовалась методом $\mathrm{ACM}$ с использованием сканирующего зондового микроскопа SMENA-A (платформа Solver, 3АО НТ-МДТ, Россия) как в полуконтактной, так и в контактной модах при комнатной температуре. В последнем случае использование метода латеральных сил позволяет различать области со своими коэффициентами трения и особенности рельефа поверхности образца, его мелких деталей. При изучении физико-химических свойств поверхности он полезен для контроля примесных фаз, сильно отличающихся по своим свойствам. Интерпретация изменения локальных сил трения и изменения физико-химических свойств поверхности образца возможна только на очень гладких образцах. Метод отображения фазы связан с использованием резонансных колебаний кантилевера. Фазовый сдвиг колебаний кантилевера определяется энергией диссипативного взаимодействия кантилевера с поверхностью образца (адгезионные, капиллярные и другие силы). Изменение фазы колебаний записывается в виде распределения фазового контраста, если поверхность образца является неоднородной по своим свойствам. Поскольку в нижней точке колебаний кантилевер механически взаимодействует с поверхностью образца, на изменение амплитуды и фазы колебаний существенно влияет локальная жесткость поверхности [16]. Но, так же как и в случае метода латеральных сил, возможная интерпретация распределения фазового контраста по поверхности образца будет правильной только на гладких образцах, что вызывало необходимость выбора малых $($ до $0.7 \times 0.7 \mu \mathrm{m})$ гладких участков сканирования и проведения сканирования с малыми скоростями. Сканирование поверхности осуществлялось стандартными кремниевыми зондами (кантилеверами) HA_NC ETALON c длиной от 80 до $110 \mu \mathrm{m}$ с резонансными частотами $(\mathrm{F})$ от 140 до $235 \mathrm{kHz}$, радиусом закругления острия $10 \mathrm{~nm}$ и константами жесткости 3.5-12 N/m (ЗАО НТ-МДТ, Россия). Исследовались как шлифованная поверхность, так и сколы образцов. Полученные АСМ изображения поверхностей обрабатывались программными средствами визуализации и анализа Nova_1443 и Nova_Px 2.0. АСМ сканы поверхности исследуемых образцов, полу- ченные этим методом, позволяют воспроизводить трехмерную структуру поверхности с высоким разрешением. Оценка размеров и формы зерен проводилась как с помощью анализа полученных 2D- и 3D-профилей сечения, так и с помощью программной компоненты Grain Analysis. 3D-пространственные морфологические исследования позволили выявить пространственную анизотропию структуры. Программа Nova_Px_2 Analysis позволяет находить основные геометрические параметры частиц, такие как площадь сечения, объем, средний размер по осям, периметр, диаметр и т.д. Нами было выбрано построение гистограмм распределения частиц по диаметрам.

\section{Намагниченность и МКЭ}

Термомагнитный анализ образцов проводился в малом поле 200 Ое в температурном интервале от 4.2 до $400 \mathrm{~K}$ на стандартном СКВИД-магнетометре. Изотермические измерения полевых зависимостей намагниченности образцов проводились на Биттеровском магнитометре в магнитных полях до $140 \mathrm{kOe}$ (Международная лаборатория сильных магнитных полей и низких температур, Вроцлав, Польша).

Измерения МКЭ проводились прямым методом в магнитных полях до $18 \mathrm{kOe}$ в интервале температур от 80 до $350 \mathrm{~K}$ с использованием установки MagEq MMS 901 (OOO Полимагнит группы компаний AMT\&C, Россия) и косвенным методом, с использованием самого распространенного подхода определения величины МКЭ, путем обработки экспериментально полученных полевых зависимостей намагниченности образцов, измеренных при различных температурах, применяя уравнения Максвелла.

\section{3. Результаты и обсуждение}

Рентгеноструктурный анализ отожженных образцов показал, что все полученные многокомпонентные соединения $\mathrm{Tb}_{0.3} \mathrm{Dy}_{0.35} \mathrm{Ho}_{0.35} \mathrm{Co}_{1.75} \mathrm{~T}_{0.25}(T=\mathrm{Fe}, \mathrm{Al})$ являются однофазными. Исследование методом АСМ топологии поверхности образцов исходного соединения $\mathrm{Tb}_{0.3} \mathrm{Dy}_{0.35} \mathrm{Ho}_{0.35} \mathrm{Co}_{2}$, a также образцов с частичным замещением кобальта железом и алюминием, позволило проанализировать их структурные особенности. Исследования проводились в микронном (при размере скана более $50 \times 50 \mu \mathrm{m}$ и более) и наноразмерном (размер исследуемой области составлял порядка $3 \times 3 \mu \mathrm{m})$ масштабах. АСМ снимки топологии поверхности в микронном масштабе позволили оценить особенности рельефа поверхности, отражающего его структуру. АСМ снимки в наномасштабе позволили оценить размеры зерен, которые составляют десятки и сотни нанометров. Результаты полученных особенностей рельефа поверхности образцов представлены на рис. 1 .

На поверхности трех образцов соединений на микроуровне наблюдается неоднородная направленная структура (рис. 1,a). Анализ полученных результатов на 


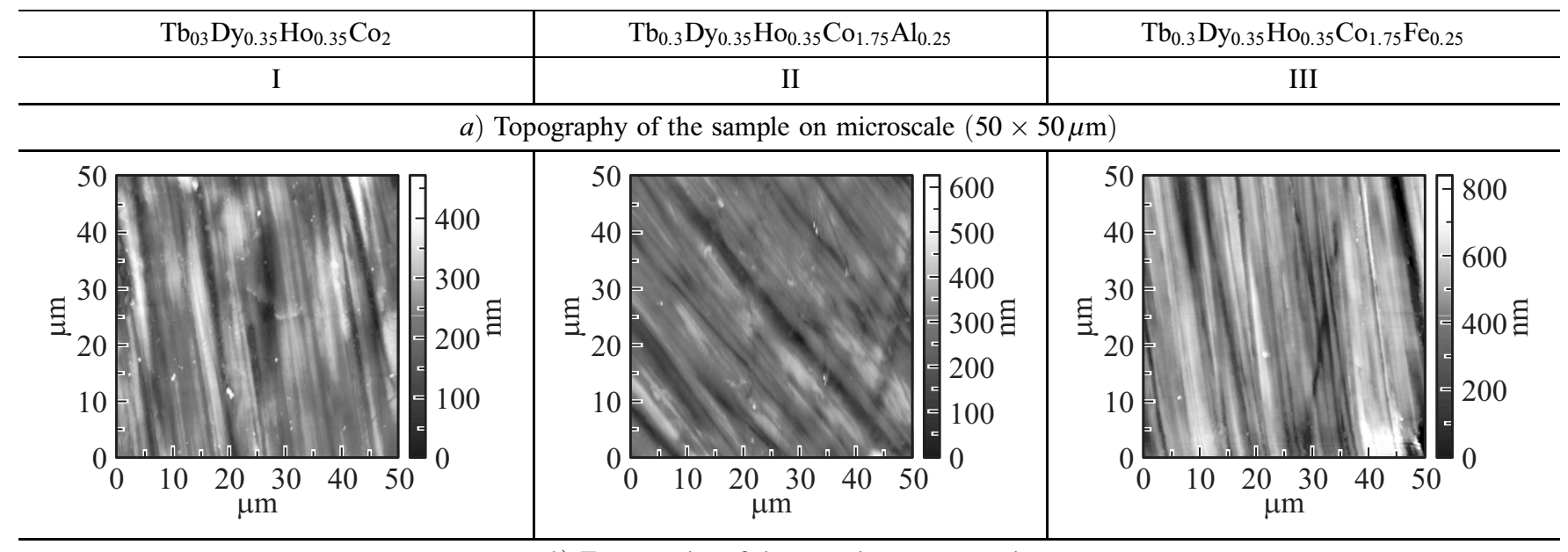

b) Topography of the sample on nanoscale
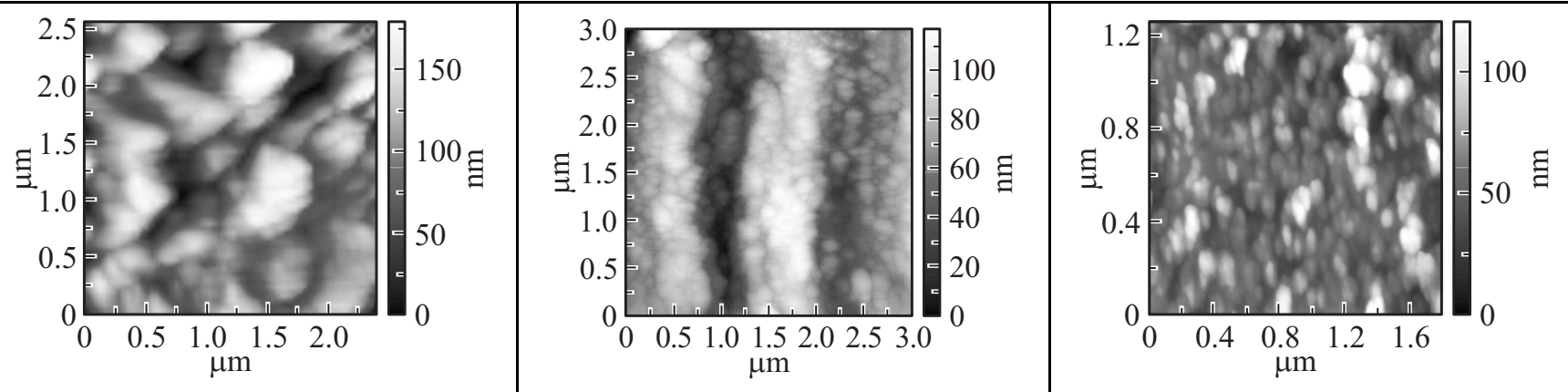

c) Section analysis of the sample's surface on nanoscale
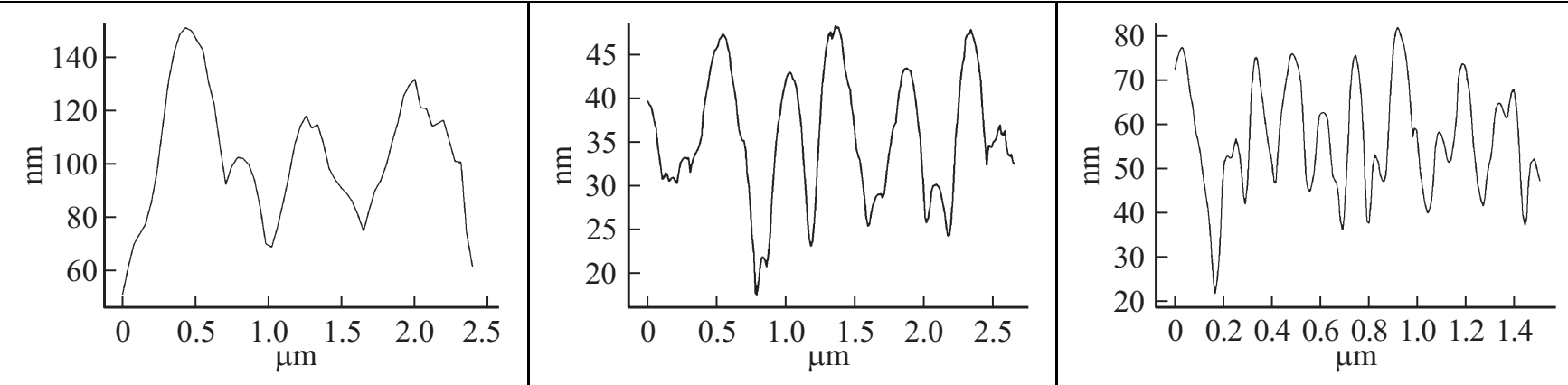

d) Topography of the 3D sample's surface on nanoscale
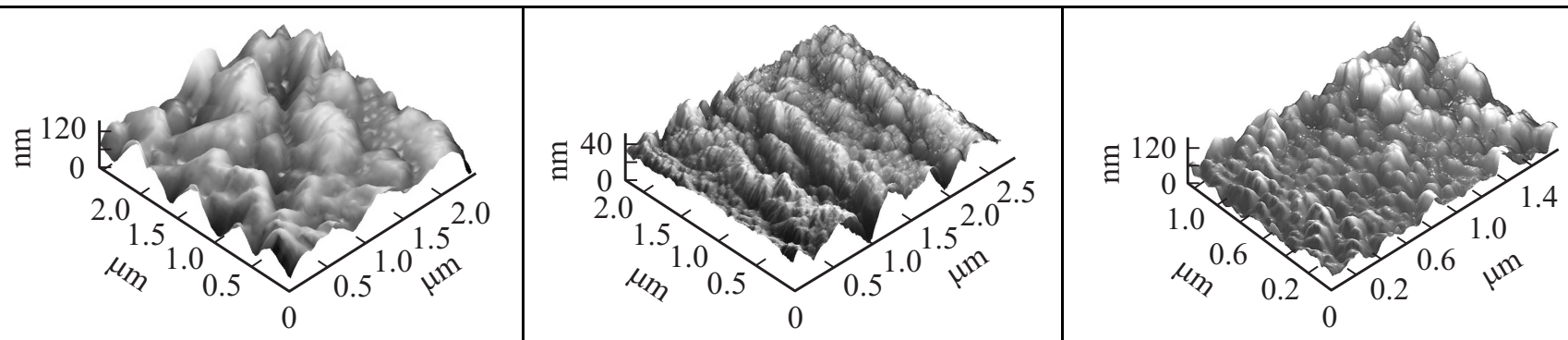

Рис. 1. Топология поверхности на микро- $(a)$ и наноуровне $(b)$, профиль сечения образцов $(c)$, 3D-изображение поверхностей $(d)$, распределение зерен по среднему диаметру $(e)$ синтезированных фаз Лавеса $\mathrm{RCo}_{2} . \mathrm{I}$ - исходное соединение, II - c Al, III - c Fe.

микронном уровне позволяет сделать вывод об аналогии топографической структуры поверхностей всех трех исследованных образцов. Метод латеральных сил подтвердил наличие только одной фазы. На наноуровне (рис. $1, b)$ поверхность всех трех исследуемых образцов имеет зернистую структуру. Наряду с анализом 2D-изоб- 


\begin{tabular}{c|c|c}
\hline $\mathrm{Tb}_{03} \mathrm{Dy}_{0.35} \mathrm{Ho}_{0.35} \mathrm{Co}_{2}$ & $\mathrm{~Tb}_{0.3} \mathrm{Dy}_{0.35} \mathrm{Ho}_{0.35} \mathrm{Co}_{1.75} \mathrm{Al}_{0.25}$ & $\mathrm{~Tb}_{0.3} \mathrm{Dy}_{0.35} \mathrm{Ho}_{0.35} \mathrm{Co}_{1.75} \mathrm{Fe}_{0.25}$ \\
\hline $\mathrm{I}$ & $\mathrm{II}$ & $\mathrm{III}$ \\
\hline
\end{tabular}

e) Grain analysis
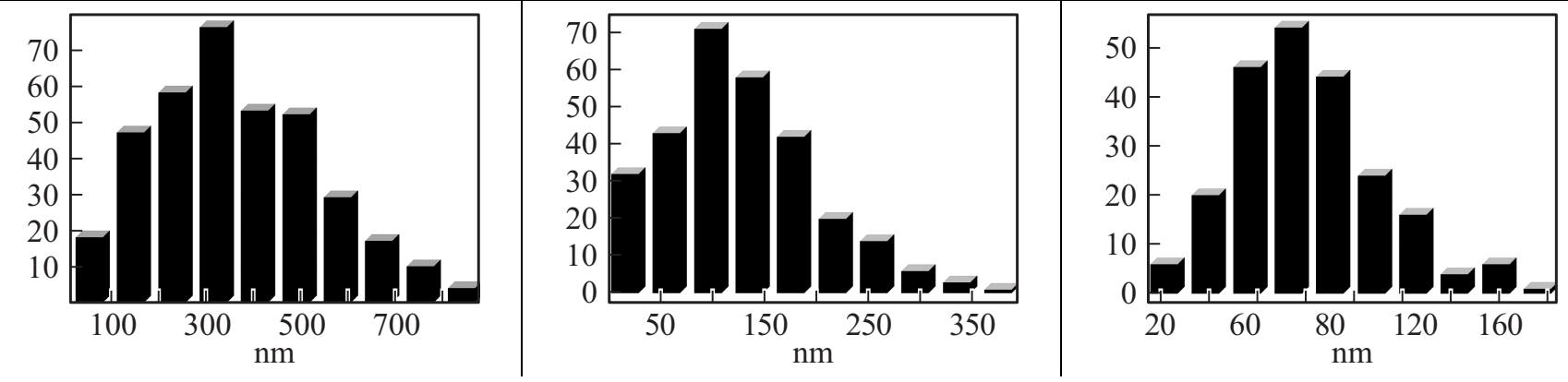

Рис. 1 (продолжение)

ражений для более полной оценки размеров и формы зерен с помощью программного средства визуализации и анализа Nova_1443 построены объемные изображения поверхности и профиль сечения. Данная операция проводилась для всех трех соединений (рис. 1,c,d). Зерна на поверхности исходного образца $\mathrm{Tb}_{0.3} \mathrm{Dy}_{0.35} \mathrm{Ho}_{0.35} \mathrm{Co}_{2}$ размерами от $300 \mathrm{~nm}$ до $1 \mu \mathrm{m}$ имеют сплюснутую овальную форму. Они собраны в конгломераты, напоминающие кластеры, размерами несколько микрон (рис. $1, b(\mathrm{I})$ )

В образцах с алюминием хорошо видны зерна эллипсоидальной формы разных размеров (рис. 1 (II)). Из анализа полученных изображений и профиля сечения установлено, что в среднем их размеры по оси $X$ имеют разброс от 100 до $250 \mathrm{~nm}$, а по оси $Y$ - от 70 до $120 \mathrm{~nm}$. В образце $\mathrm{Tb}_{0.3} \mathrm{Dy}_{0.35} \mathrm{Ho}_{0.35} \mathrm{Co}_{1.75} \mathrm{Fe}_{0.25}$ с частичным замещением кобальта на железо зерна поверхности образца приобретают более правильную округлую форму, их средний размер значительно уменьшается и составляет в среднем около $90 \mathrm{~nm}$ (рис. 1 (III)). В обоих составах зерна так же, как и в исходном, образуют конгломераты.

Средний диаметр зерен для всех трех образцов был также определен при помощи программной компоненты Grain Analysis и составил для исходного сплава $\mathrm{Tb}_{0.3} \mathrm{Dy}_{0.35} \mathrm{Ho}_{0.35} \mathrm{Co}_{2} \quad 720 \mathrm{~nm}$, $\mathrm{a}$ для образцов $\mathrm{Tb}_{0.3} \mathrm{Dy}_{0.35} \mathrm{Ho}_{0.35} \mathrm{Co}_{1.75} \mathrm{Al}_{0.25}$ и $\mathrm{Tb}_{0.3} \mathrm{Dy}_{0.35} \mathrm{Ho}_{0.35} \mathrm{Co}_{1.75} \mathrm{Fe}_{0.25} 143$ и $77 \mathrm{~nm}$ соответственно. На рис. 1,e показаны результаты данного анализа, представляющие распределение диаметра зерен в виде гистограммы. Как видно, результаты различных обработок изображений, определение размера зерен хорошо согласуются между собой.

Процесс затвердевания металлического расплава это процесс кристаллизации, поэтому подробное изучение формы и структуры зерна дает важную информацию о ее влиянии на механические, электрические, оптические и многие другие физические свойства полученного сплава, а также позволяет судить об особенностях металлургического процесса его получения. Анализ структуры зерна исходного состава $\mathrm{Tb}_{0.3} \mathrm{Dy}_{0.35} \mathrm{Ho}_{0.35} \mathrm{Co}_{2}$,

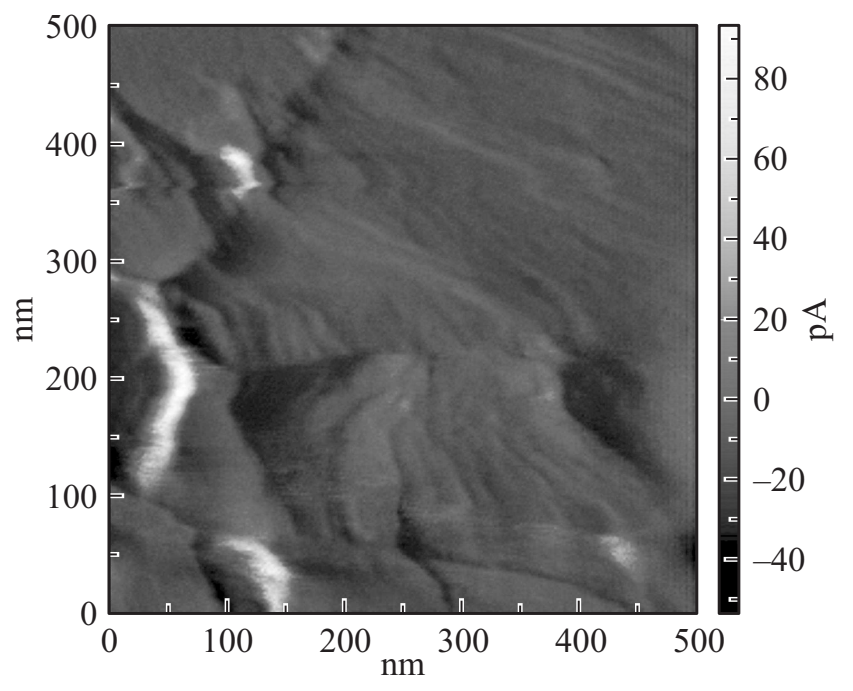

Рис. 2. Террасно-ступенчато-слоистая структура зерен $\mathrm{Tb}_{0.3} \mathrm{Dy}_{0.35} \mathrm{Ho}_{0.35} \mathrm{Co}_{2}$.

проведенный контактным методом по методике латеральных сил на очень гладком свежем сколе, показал террасно-ступенчато-слоистую структуру зерна (рис. 2). Данная структура на микроуровне наблюдается для ряда различных металлов и сплавов и в некоторых случаях при неблагоприятных климатических условиях приводит к расслаиванию (слоистой форме коррозии), происходящему вследствие быстрого бокового воздействия вдоль границ слоев, расположенных параллельно поверхности металла внутри самих зерен. Примерный размер террасы составил $80-100 \mathrm{~nm}$, а средняя высота ступеньки - 3-10 nm, что говорит о параллельном перемещении грани кристалла во время его роста, происходящем вследствие того, что скорость перемещения ступенек (тангенциальная составляющая) в несколько раз превышает нормальную составляющую скорости.

Таким образом, наши АCM исследования показали, что размер и форма зерен всех трех изученных образцов сильно отличаются друг от друга. Анализ полученных 


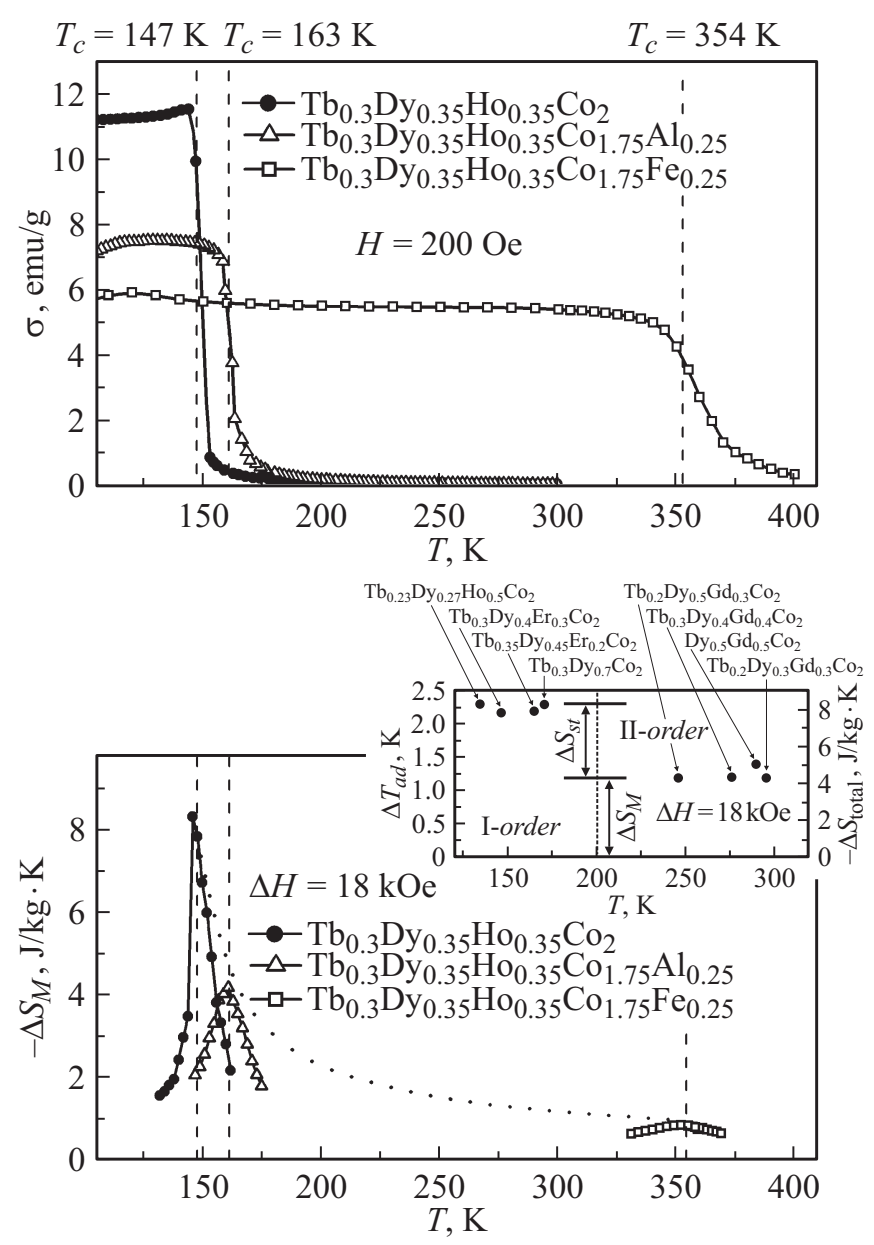

Рис. 3. Термомагнитный анализ (вверху) и температурная зависимость изменения энтропии (внизу) соединений $\mathrm{Tb}_{0.3} \mathrm{Dy}_{0.35} \mathrm{Ho}_{0.35} \mathrm{Co}_{2}, \mathrm{~Tb}_{0.3} \mathrm{Dy}_{0.35} \mathrm{Ho}_{0.35} \mathrm{Co}_{1.75} \mathrm{Al}_{0.25}$ и $\mathrm{Tb}_{0.3} \mathrm{Dy}_{0.35} \mathrm{Ho}_{0.35} \mathrm{Co}_{1.75} \mathrm{Fe}_{0.25}$. На вставке - МКЭ в соединениях $\mathrm{RR}^{\prime} \mathrm{R}^{\prime} \mathrm{Co}_{2}[5]$.

изображений показал, что во всех трех образцах зерна объединяются в конгломераты. Подобное кластерное образование из единичных зерен может существенно сказаться на многих свойствах, в том числе магнитных.

Мы рассмотрели особенности морфологии поверхности исследуемых образцов на микро- и наноуровне, теперь перейдем к рассмотрению их магнитных свойств. Проведенный термомагнитный анализ в магнитном поле $200 \mathrm{Oe}$ (рис. 3) подтвердил однофазность образцов и позволил определить температуру Кюри $\left(T_{C}\right)$ исследуемых соединений по экстремуму на кривой температурной зависимости производной намагниченности $d \sigma / d T$. Полученные температуры Кюри соединений $\mathrm{Tb}_{0.3} \mathrm{Dy}_{0.35} \mathrm{Ho}_{0.35} \mathrm{Co}_{2}, \mathrm{~Tb}_{0.3} \mathrm{Dy}_{0.35} \mathrm{Ho}_{0.35} \mathrm{Co}_{1.75} \mathrm{Al}_{0.25}$ и $\mathrm{Tb}_{0.3} \mathrm{Dy}_{0.35} \mathrm{Ho}_{0.35} \mathrm{Co}_{1.75} \mathrm{Fe}_{0.25}$ равны 147,163 и $354 \mathrm{~K}$ соответственно. Магнитные свойства исходного соединения $\mathrm{Tb}_{0.3} \mathrm{Dy}_{0.35} \mathrm{Ho}_{0.35} \mathrm{Co}_{2}$ были подробно изучены нами ранее [3]. Частичное замещение кобальта на алюминий приводит к небольшому росту температуры Кюри на $16 \mathrm{~K}$, в то время как замещение кобальта на железо приводит к значительному возрастанию $T_{C}$ (на $207 \mathrm{~K}$ ). Таким образом, проведенные выше исследования АСМ были проведены на образцах в парамагнитном состоянии в случае исходного сплава $\mathrm{Tb}_{0.3} \mathrm{Dy}_{0.35} \mathrm{Ho}_{0.35} \mathrm{Co}_{2}$ и сплава c алюминием, а также на образцах в магнитном состоянии в случае сплава с железом. Температуры Кюри данных соединений определяются величинами обменных

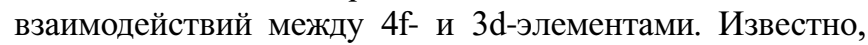
что в железосодержащих соединениях типа $\mathrm{RFe}_{2}$ преобладает вклад в температуру Кюри от 3d-3d обменных взаимодействий, в то время как в кобальтсодержащих соединениях типа $\mathrm{RCo}_{2}$ основным является вклад от 4f-3d. Конкуренцией этих двух вкладов и изменением электронной структуры и объясняется наблюдаемый рост температуры Кюри при замещениях в 3d-подрешетке.

Для всех трех соединений методом термодинамических коэффициентов [5] был определен род фазового перехода из магнитоупорядоченного в магниторазупорядоченное состояние. Установлено, что исходное соединение демонстрирует переход первого рода. Частичное замещение кобальта как на алюминий, так и на железо приводит к смене рода фазового перехода с первого на второй.

Известно, что соединения типа $\mathrm{RCo}_{2}$ в области температуры Кюри могут демонстрировать большой по величине МКЭ [17-20]. Если в соединении произошел переход из магнитоупорядоченной фазы в магниторазупорядоченную фазу первого рода, то при изменении внешнего магнитного поля в области температуры перехода может происходить большое выделение или поглощение тепла. Этот эффект наблюдается в узком интервале температур. При магнитофазовых переходах второго рода величина МКЭ ниже, однако рабочий интервал температур, на котором он проявляется, заметно уширяется.

Кроме широкого интервала рабочих температур, для дальнейшего технического применения подобных материалов очень важна температура, при которой наблюдается наибольший МКЭ, и возможность ее варьирования. Изменить значение $T_{C}$ в соединениях типа $\mathrm{RCo}_{2}$, как было показано ранее, возможно с помощью замещений в Р3 подрешетке. В зависимости от комбинации редкоземельных металлов, входящих в состав сплава, изменяется как температура магнитного фазового перехода, так и род перехода. Как показали наши предыдущие исследования магнитокалорических свойств соединений подобного класса [4], соединения с переходом первого рода демонстрируют изменение энтропии $-\Delta S$, примерно равное $8 \mathrm{~J} / \mathrm{kg} \cdot \mathrm{K}$. Замещение $\mathrm{Tb}$, Dy, Но атомами $\mathrm{Gd}$ приводит к сильному возрастанию значения $T_{C}$, вплоть до комнатной температуры, смене рода перехода на второй и уменьшению величины изменения энтропии $-\Delta S$ в 2 раза (вставка к рис. 3). Полное изменение энтропии системы складывается из изменения ее магнитной и структурной составляющих: $\Delta S_{\text {total }}=\Delta S_{\text {mag }}+\Delta S_{\mathrm{st}}$. При смене рода перехода в соединениях типа $\mathrm{RCo}_{2}$ структурная составляющая становится близка к нулю, и полное изменение энтропии уменьшается. 
Для всех трех исследуемых соединений $\mathrm{Tb}_{0.3} \mathrm{Dy}_{0.35} \mathrm{Ho}_{0.35} \mathrm{Co}_{2}, \quad \mathrm{~Tb}_{0.3} \mathrm{Dy}_{0.35} \mathrm{Ho}_{0.35} \mathrm{Co}_{1.75} \mathrm{Al}_{0.25} \quad$ и $\mathrm{Tb}_{0.3} \mathrm{Dy}_{0.35} \mathrm{Ho}_{0.35} \mathrm{Co}_{1.75} \mathrm{Fe}_{0.25}$ в области температуры Кюри рассчитаны температурные зависимости изменения энтропии (косвенный метод) и получены температурные зависимости адиабатического изменения температуры при изменении внешнего магнитного поля до $18 \mathrm{kOe}$ (прямой метод). В исходном соединении $\mathrm{Tb}_{0.3} \mathrm{Dy}_{0.35} \mathrm{Ho}_{0.35} \mathrm{Co}_{2}$ величина эффекта $(-\Delta S)$ составляет $8.4 \mathrm{~J} / \mathrm{kg} \cdot \mathrm{K}$, в соединении с алюминием эффект уменьшается в 2 раза и равен $4.3 \mathrm{~J} / \mathrm{kg} \cdot \mathrm{K}$. Но самое большое изменение происходит в соединении с железом, где эффект уменьшается практически на порядок $(-\Delta S=1.0 \mathrm{~J} / \mathrm{kg} \cdot \mathrm{K})$. Хотя в нашем распоряжении было только три состава, анализ результатов показывает, что уменьшение эффекта происходит по закону, близкому к гиперболическому. Однако для точного вывода необходим анализ большего количества образцов как с магнитными, так и немагнитными замещениями в 3d-подрешетке. При замещении в подрешетке кобальта происходит изменение электронной структуры и сдвиг уровня Ферми [21].

Проведенный расчет изменения энтропии (косвенный метод определения МКЭ) в изучаемых в настоящей работе соединениях хорошо согласуется с прямым методом измерения МКЭ.

\section{Заключение}

Получены однофазные образцы соединений типа фаз Лавеса с частичными замещениями кобальта на алюминий и железо: $\mathrm{Tb}_{0.3} \mathrm{Dy}_{0.35} \mathrm{Ho}_{0.35} \mathrm{Co}_{2}, \quad \mathrm{~Tb}_{0.3} \mathrm{Dy}_{0.35} \mathrm{Ho}_{0.35} \mathrm{Co}_{1.75} \mathrm{Al}_{0.25}$ и $\mathrm{Tb}_{0.3} \mathrm{D}_{0.35} \mathrm{Ho}_{0.35} \mathrm{Co}_{1.75} \mathrm{Fe}_{0.25}$. На микронном уровне методом атомно-силовой микроскопии на поверхности образцов обнаружена неоднородная направленная структура, сходная для всех трех соединений. Анализ полученных АCM изображений в наномасштабе позволил оценить форму и размер зерен синтезированных фаз. Установлено, что при частичном замещении кобальта на алюминий и железо размер зерна уменьшается, а сами зерна объединяются в конгломераты. Анализ структуры зерна для $\mathrm{Tb}_{0.3} \mathrm{Dy}_{0.35} \mathrm{Ho}_{0.35} \mathrm{Co}_{2}$ показал его террасноступенчато-слоистую структуру.

Установлено, что частичное замещение (на 12.5 wt.\%) в подрешетке 3d-атомов приводит не только к диспергированию структуры, но и к изменению функциональных свойств, а именно повышению температуры Кюри и снижению магнитокалорического эффекта. Установлена связь магнитных и магнитокалорических свойств со структурными особенностями образцов, наблюдаемыми на микро- и наноуровнях.

Работа выполнена при поддержке проекта РФФИ и правительства Москвы № 15-33-70040 мол_а_мос.

\section{Список литературы}

[1] Илюшин А.С. Основы структурной физики редкоземельных интерметаллических соединений. М. Изд-во МГУ, 2005. $174 \mathrm{c}$.

[2] Gratz E., Markosyan A.S. // J. Phys. Condens. Matter. 2001. Vol. 13. N 23. P. R385-R413.

[3] Политова Г.А., Чжсан В.Б., Терешина И.С., Бурханов Г.С., Манаков А.А., Алексеева О.А., Филимонов А.В., Илюшин А.С. // ФТТ. 2015. Т. 57. Вып. 12. С. 57-62.

[4] Gschneidner K.A., Mudryk Jr.Y., Pecharsky V.K. // Scripta Mater. 2012. Vol. 67. N 6. P. 572-577.

[5] Tereshina I., Cwik J., Tereshina E., Politova G., Burkhanov G., Chzhan V., Ilyushin A., Miller M., Zaleski A., Nenkov K., Schultz L. // IEEE Trans. Mag. 2014. Vol. 50. N 11. P. 2504604.

[6] Политова Г.А., Терешина И.С., Бурханов Г.С., Чистяков О.Д., Чжсан В.Б., Нижсанковский В.И., Залески А., Каминская Т.П., Попов В.В. // ФТТ. 2011. Т. 53. Вып. 10. C. $1925-1928$.

[7] Бурханов Г.С., Терешина И.С., Политова Г.А., Чистяков О.Д., Друлис Г., Залески А. // ДАН. 2011. Т. 440. № 5. C. 611-614.

[8] Tereshina I.S., Politova G.A., Tereshina E.A., Burkhanov G.S., Chistyakov O.D., Nikitin S.A. // J. Phys. Conf. Series. 2011. Vol. 266. N 1. P. 012077.

[9] Tereshina I., Politova G., Tereshina E., Cwik J., Nikitin S., Chistyakov O., Karpenkov A., Karpenkov D., Palewski T. // J. Phys.: Conf. Series. 2011. Vol. 303. P. 012024.

[10] Tereshina I.S., Nikitin S.A., Politova G.A., Ilyushin A.S., Opolenko A.A., Burkhanov G.S., Chistyakov O.D., Palewski T. // Sol. St. Phenomen. Series. 2009. Vol. 152-153. P. 7-10.

[11] Tereshina I., Politova G., Tereshina E., Nikitin S., Burkhanov G., Chistyakov O., Karpenkov A. // J. Phys. Conf. Series. 2010. Vol. 200. P. 092012.

[12] Терешина И.С., Никитин С.А., Политова Г.А., Опаленко А.А., Терешина Е.А., Телегина И.В. // ФТТ. 2009. Т. 51. Вып. 1. С. 85-90.

[13] Терешина И.С., Туляков А.П., Никитин С.А., Политова Г.А., Скоков К.П. // ФТТ. 2007. Т. 49. Вып. 2. С. 304-308.

[14] Александрян В.В., Белов К.П., Левитин Р.З., Маркосян А.С., Снегирев В.В. // Письма в ЖЭТФ. 1984. Т. 40. Вып. 2. С. 77-80.

[15] Андреева Н.В., ФилимоновА.В., Рудской А.И., Бурханов Г.С., Терешина И.С., Политова Г.А., Пелевин И.А. // ФТТ. 2016. Т. 58. Вып. 9. С. 1798-1805.

[16] Миронов В.Л. Основы сканирующей зондовой микроскопии. Н. Новгород: Ин-т физики микроструктур РАН, 2004. $110 \mathrm{c}$.

[17] Gschneidner K.A., Pecharsky V.K., Tsokol A.O. // Rep. Prog. Phys. 2005. Vol. 68. P. 1479-1539.

[18] Tishin A.M., Spichkin Y.I. The magnetocaloric Effect and its Applications, Institute of Physics. Bristol: IOP publishing Ltd, 2003. $476 \mathrm{p}$.

[19] Никитин С.А. Магнитные свойства редкоземельных металлов и их сплавов. М.: Изд-во МГУ, 1989. 248 с.

[20] Khmelevkyi S., Mohn P.J. // Phys. Condens. Matter. Vol. 12. N 45. P. 9453-9464.

[21] Tereshina I.S., Chzhan V.B., Tereshina E.A., Khmelevskyi S., Burkhanov G.S., Ilyushin A.S., Paukov M.A., Havela L., Karpenkov A.Yu., Cwik J., Koshkid'ko Yu.S., Miller M., Nenkov K., Schultz L. // J. Appl. Phys. 2016. Vol. 120. P. 013901. 